\title{
Retropharyngeal Abscess in a Fourteen-Month-Old Child Presenting with Dysphagia and Obstructive Sleep Apnea: A Case Report
}

\author{
Zahar Alkhadem ${ }^{\mathrm{a}}$ Lubna Lutfi $^{\mathrm{a}}$ Doha Ali ${ }^{\mathrm{a}}$ Asma Anan Mohammed ${ }^{\mathrm{a}}$ \\ Iyad Said Hamadi ${ }^{\text {b }}$
}

${ }^{a}$ Medical Internship Program, Medical Education Department, Dubai Health Authority, Dubai, UAE; ${ }^{\mathrm{b}}$ Ear Nose Throat Department, Dubai Hospital, Dubai Health Authority, Dubai, UAE

\section{Keywords}

Abscess · Retropharyngeal abscess · Deep neck infection · Pediatric infection

\begin{abstract}
Retropharyngeal abscess is a relatively uncommon midline deep neck space infection that extends from the base of the skull to the posterior mediastinum, situated between the buccopharyngeal and alar fascias. In this case report, we present a 14-month-old previously healthy female patient who had a high-grade fever for 7 days, associated with neck stiffness and restriction of neck movements to the right side. Her parents noticed decreased oral intake associated with dysphagia, muffled quality of voice, and obstructive sleep apnea. However, the patient had no clinical signs of mechanical obstruction on examination. A contrast-enhanced computed tomography scan of the neck showed a large retropharyngeal septated fluid collection measuring $8 \times 3 \times 6 \mathrm{~cm}$, which was categorized as a large retropharyngeal abscess that was complicated by descending mediastinitis. The patient was taken immediately to the operation theater for incision and drainage under general anesthesia, after which she was started on intravenous antibiotics.
\end{abstract}

(c) 2021 The Author(s).

Published by S. Karger AG, Basel

karger@karger.com www.karger.com/dmj

Karger $\stackrel{\text { ' }}{5}$
(C) 2021 The Author(s)

Published by S. Karger AG, Basel

This is an Open Access article licensed under the Creative Commons Attribution-NonCommercial-4.0 International License (CC BY-NC) (http://www.karger.com/Services/OpenAccessLicense), applicable to the online version of the article only. Usage and distribution for commercial purposes requires written permission.

\section{Introduction}

Retropharyngeal abscess (RPA) is a relatively uncommon midline deep neck space infection that extends from the base of the skull to the posterior mediastinum, situated between the buccopharyngeal and alar fascias [1]. The incidence of RPA increased from 2.98 per 100,000 population among children $<20$ years in 2003 to 4.10 per 100,000 in 2012 [2]. Due to the widespread use of antibiotics, such cases have become less prevalent [3], and most physicians may be rather unfamiliar with the diagnosis; however, it still has high morbidity and mortality rates. Usually occurring in children between the ages of 3 and 5 years [4], it is often preceded by an upper respiratory tract infection involving the retropharyngeal lymph nodes and leading to suppuration and perforation into the retropharyngeal space. These lymph nodes undergo atrophy after the age of 5 years [5], making this an uncommon infection in adults. Nevertheless, local trauma may serve as a likely etiology in this age-group [6]. The typical presentation consists of high fever, dysphagia, odynophagia, drooling with decreased oral intake, trismus, and neck stiffness or wry neck [7]. In severe cases, the infection may extend into the mediastinum, and the growing abscess can result in upper airway obstruction and asphyxiation [8]. The assessment and diagnosis can be made through 


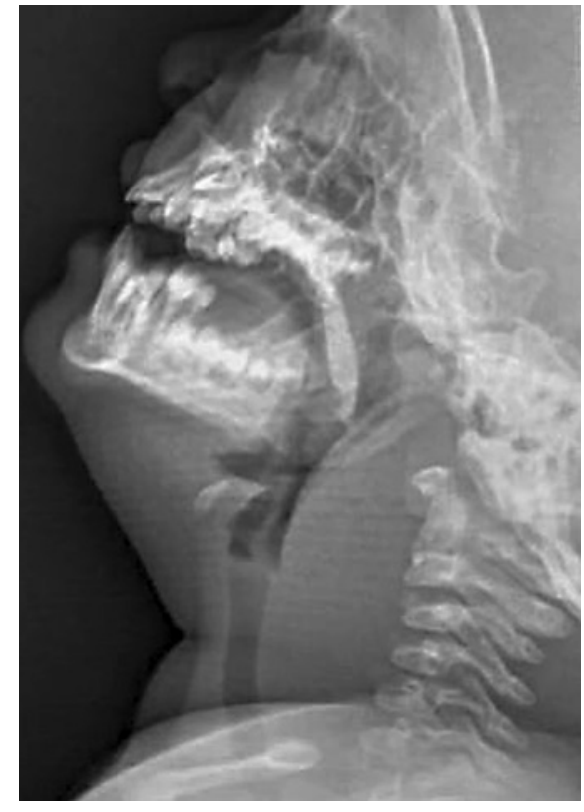

Fig. 1. Lateral neck $x$-ray showing widened cervical soft tissue in the prevertebral space.

Table 1. Ancillary laboratory testing showing only an increase in inflammatory markers

\begin{tabular}{lll}
\hline & Reference range and units & Value \\
\hline WBC count & $6.0-18.0 \times 10^{3} / \mu \mathrm{L}$ & 26.7 \\
Hemoglobin & $11.1-14.1 \mathrm{~g} / \mathrm{dL}$ & 11.9 \\
Platelet count & $200-550 \times 10^{3} / \mu \mathrm{L}$ & 618 \\
Neutrophils & $1.0-6.0 \times 10^{3} / \mu \mathrm{L}$ & 22.8 \\
Lymphocytes & $3.5-11.0 \times 10^{3} / \mu \mathrm{L}$ & 2.8 \\
CRP & $<5.0 \mathrm{mg} / \mathrm{L}$ & 71.5 \\
ESR & $0-20 \mathrm{~mm} / 1 \mathrm{~h}$ & 45
\end{tabular}

WBC, white blood cell; CRP, C-reactive protein; ESR, estimated sedimentation rate.

imaging techniques, mainly through computed tomography (CT) scan, and can provide further insight into the extent of infection and involvement of the carotid sheath and mediastinum. The mainstay of treatment is early transoral or transcervical surgical drainage and empirical antibiotic administration to eliminate infections [1].

\section{Case Report}

A 14-month-old previously healthy female infant presented to the emergency room, accompanied by her parents, with a highgrade fever that reached $40^{\circ} \mathrm{C}$ for a 7 -day duration. The parents

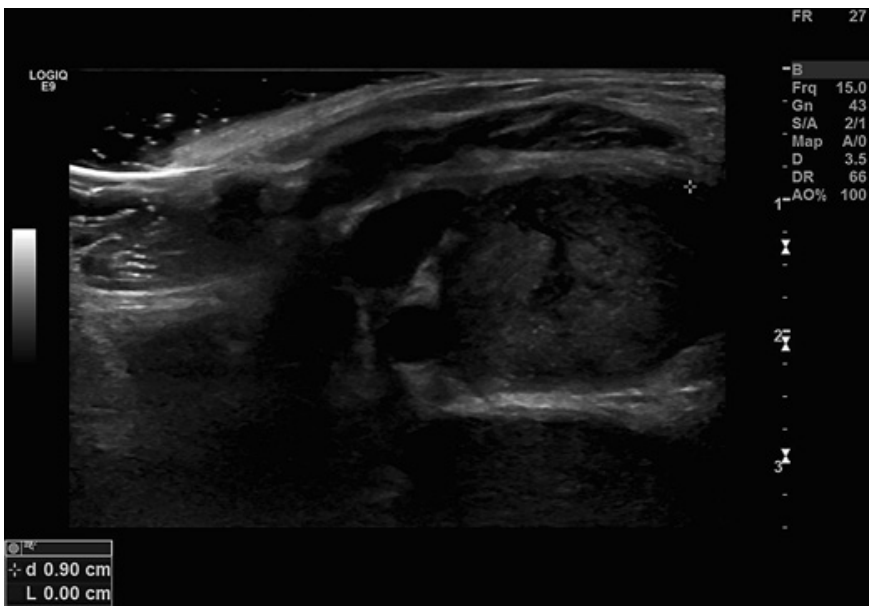

Fig. 2. Sonographic image of the retropharyngeal pus abscess; the collection has a turbid texture suggestive of pus.

had noticed that it was associated with neck stiffness, restriction of neck movements to the right, and decreased oral intake with dysphagia. In the last 2 days, her cries had started sounding muffled. Furthermore, she began exhibiting signs of obstructive sleep apnea. No history of regurgitation, drooling, vomiting, prodromal flu symptoms, any local trauma, or foreign body ingestion was reported.

She was given an acetaminophen suppository and oral ibuprofen for the fever which was initially relieved. However, as her symptoms did not improve, they took her to a local clinic 5 days later, where she received IV ceftriaxone for 2 days. She also underwent a lateral neck $\mathrm{x}$-ray that showed widened cervical soft tissue in the prevertebral space, suspicious of an abscess (Fig. 1). Due to the $\mathrm{x}$-ray findings, she was advised to visit a tertiary care center.

On general examination, the patient was afebrile and vitally stable but agitated. She was not in distress and had no increased respiratory effort or any signs of difficulty breathing. Her growth parameters were within normal ranges. Local examination of the neck revealed a mild right-side neck swelling upon inspection with restricted right lateral movement. Auscultation revealed no bruit. Examination of the throat showed enlargement of the right tonsil with bulging of the right posterior tonsillar pillar. Nose and ear examinations were insignificant. Chest wall examination revealed normal expansion, no retractions, and tympanic percussion, and no abnormal breath sounds were heard on auscultation.

Ancillary laboratory testing showed only an increase in inflammatory markers, with the remaining tests otherwise unremarkable (Table 1). An ultrasound of the neck revealed a large fluid collection in the retropharyngeal space. The bulk of the collection was identified on the right side of the neck, with a variable internal echotexture suggestive of pus (Fig. 2).

A contrast-enhanced CT scan was then performed, which showed a large retropharyngeal septated fluid collection measuring $8 \times 3 \times 6 \mathrm{~cm}$ and extending over the entire length of the cervical spine (Fig. 3). Superiorly, the collection was seen involving the tonsillar pillars with enlargement, enhancement, and rim enhancing collections denoting a peritonsillar abscess. They were seen bulging into the oropharynx on the right side. Inferiorly, the col- 


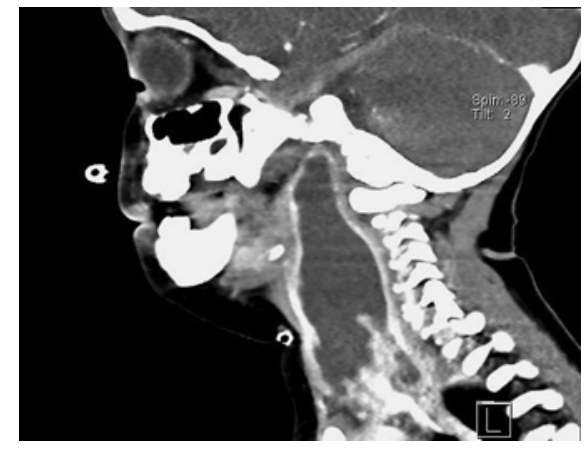

Fig. 3. Sagittal section of contrast enhanced head and neck computed tomography scan revealing large retropharyngeal septated fluid collection measuring $8 \times 3 \times 6 \mathrm{~cm}$ and extending over the entire length of the cervical spine.

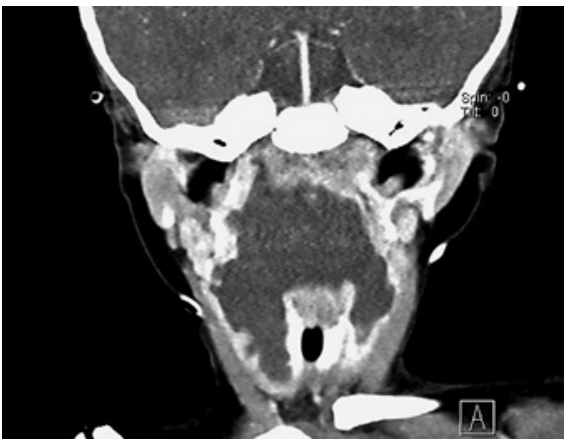

Fig. 4. Coronal section of contrast enhanced computed tomography scan of the head and neck revealing the collection extended into the superior mediastinum.

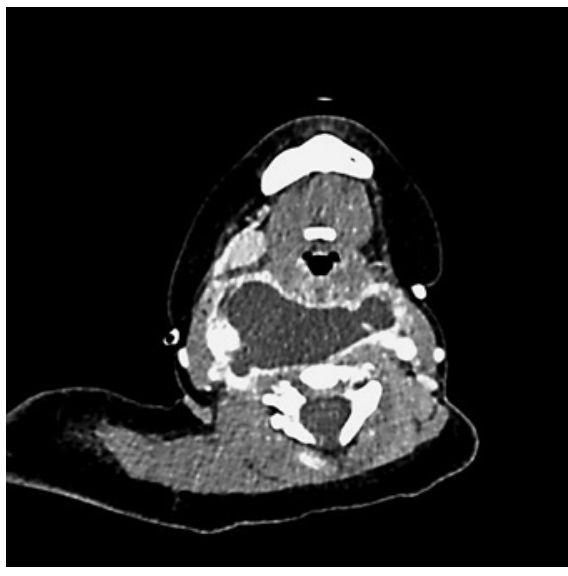

Fig. 5. Axial section of head and neck contrast enhanced computed tomography scan revealing displacement of the major neck vessels. lection extended into the superior mediastinum up to the level of the tracheal bifurcation, where it insinuated between the vessels, continuing into the anterior and middle mediastinum (Fig. 4). In addition, fluid accumulations were observed bilaterally within the eustachian tube, suggesting acute inflammation. Laterally, the scan showed posterolateral displacement of the major neck vessels (Fig. 5) and right displacement with mild compression of the trachea.

Other changes noted on imaging include enlargement of the right parotid and submandibular glands, enlarged enhancing anterior and posterior triangle cervical lymph nodes, diffuse edema of the oro- and laryngopharynx with extension to the cervical esophagus, and circumferential edema of the laryngeal wall. Airway, epiglottis, vallecula, and pyriform sinuses were preserved. A diagnosis of large retropharyngeal abscess was made, possibly arising from acute tonsillitis and peritonsillar abscess, complicated by descending mediastinitis.

The patient was taken immediately to the operation theater for incision and drainage under general anesthesia, where she was intubated. After which, the patient was admitted to the pediatrics ICU and started on empirical ceftriaxone and clindamycin. The culture taken from the pus was positive for staphylococcus aureus.

The patient improved postoperatively. Her inflammatory markers were decreasing, and she showed improvement clinically. She was discharged 10 days after admission on oral co-amoxiclav.

\section{Discussion}

RPA is a rare midline deep neck space infection that extends from the base of the skull to the posterior mediastinum. The incidence of RPA increased from 2.98 per 100,000 population among children $<20$ years in 2003 to 4.10 per 100,000 in 2012 [2]. It affects children between the ages of 3 and 5 years, with a male predominance of 2:1 [4].
There is a paucity in the literature with regard to RPA, with the majority of data derived from case reports. Information is particularly scarce within the pediatric agegroup. The largest recent case series studying retropharyngeal abscesses in the pediatric age-group was published in 2004 and studies 68 pediatric cases over a 10-year period [9]. Even so, recent advances in imaging and widespread use of antibiotics have dramatically decreased the severity of RPA and reduced the incidence of complications [10]. Historically a life-threatening condition can now be managed more efficiently if detected early.

However, the diagnosis of RPA is often delayed due to nonspecific signs and symptoms [11]. Although variable, the most common symptoms include fever, neck pain or rigidity, odynophagia, and drooling of saliva $[12,13]$. In addition, infants can present with a variable clinical picture due to an underdeveloped immune system and can be afebrile [14]. Clinical examination may reveal stridor, oropharyngeal asymmetry, a painful neck mass or swelling, and torticollis.

The physician must have a high index of suspicion and seek confirmation through supportive imaging. An inspiratory lateral airway $\mathrm{x}$-ray with neck extension has been reported to be useful as a screening study [15], but CT scan remains the gold standard imaging modality for RPA. The characteristic features of RPA on CT scan include a rim-enhancing lesion and scalloping of the abscess wall [16].

In addition, the physician must exclude other probable diagnoses such as foreign body inhalation or ingestion, epiglottitis, pharyngitis, cellulitis, neoplastic disease, and 
reactive or suppurative adenopathy. Most importantly, complications may occur if treatment is delayed. Such complications include airway compromise and obstruction, descending mediastinitis, ascending meningoencephalitis, carotid artery aneurysm, jugular vein thrombosis, sepsis, and acute respiratory distress syndrome.

A comprehensive treatment team composed of an otolaryngologist, anesthetist, critical care specialist, and radiologist is needed for appropriate management of such cases. Treatment is by immediate transoral or transcervical surgical drainage of the abscess with or without tonsillectomy [17], though some articles have stated that conservative management with antibiotics may be attempted as a first-line treatment for noncomplicated abscesses. A study showed an abscess larger than $2.5 \mathrm{~cm}$ will warrant a need of surgical intervention [18-20].

The novelty of this case lies in the fact that our patient complained of dysphagia and obstructive sleep apnea, however had no clinical signs of difficulty breathing, despite the large size of the abscess. The reason being that the collection extended directly from the retropharyngeal space toward the parapharyngeal spaces bilaterally, which explains why there was no mechanical obstruction of breathing. The early and efficient surgical intervention that was implemented emergently helped control the symptoms and prevent exacerbation of signs and symptoms that otherwise could have occurred had the abscess been neglected.

\section{Conclusion}

Retropharyngeal abscess is a relatively uncommon midline deep neck space infection, and it is often preceded by an upper respiratory tract infection. The infection may extend into the mediastinum, and the growing abscess can result in upper airway obstruction and asphyxiation. However, the physician must have a high index of suspicion for diagnosing a case such as ours which presented with symptoms of dysphagia and obstructive sleep apnea but on clinical examination demonstrated no signs of difficulty breathing. It is highly advisable to then seek confirmation for diagnosing through supportive imaging, relying on CT scan of the neck as the gold standard. The mainstay of treatment is early transoral or transcervical surgical drainage and antibiotic administration to eliminate infections and prevent complications and exacerbation of signs and symptoms.

\section{Statement of Ethics}

All personally identifying information, such as name, was excluded from the study. Written informed consent was obtained from the patient's legal guardians for publication of this case report and any accompanying images.

\section{Conflict of Interest Statement}

The authors have no conflicts of interest to declare.

\section{Funding Sources}

No funding sources were required as no costs were incurred during the preparation and submission of the manuscript.

\section{Author Contributions}

I.S.H. contributed to the conception of the case report. L.L. contributed to the abstract and conclusion. A.A.M. contributed to the introduction and case report. Z.A. contributed to the case report. D.A. contributed to the discussion.

\section{Data Availability Statement}

All data generated or analyzed during this study are included in this article. Further inquiries can be directed to the corresponding author.

\section{References}

Retropharyngeal Abscess: A Case Report
1 Jain H, Knorr TL, Sinha V. Retropharyngeal abscess. Treasure Island (FL): StatPearls Publishing; 2020.

2 Woods CR, Cash ED, Smith AM, Smith MJ, Myers JA, Espinosa CM, et al. Retropharyngeal and parapharyngeal abscesses among children and adolescents in the united states: epidemiology and management trends, 20032012. J Pediatr Infect Dis Soc. 2016 Sep;5(3): 259-68.
3 Reynolds SC, Chow AW. Severe soft tissue infections of the head and neck: a primer for critical care physicians. Lung. 2009;187(5): 271-9.

4 Elsherif AM, Park AH, Alder SC, Smith ME, Muntz HR, Grimmer F. Indicators of a more complicated clinical course for pediatric patients with retropharyngeal abscess. Int J Pediatr Otorhinolaryngol. 2010;74(2):198-201. 
5 AlAli A, Almulhim M, Alghamidi A. Visual diagnosis of retropharyngeal abscess. SJEMed. 2020;1(1):30-1.

6 Harkani A, Hassani R, Ziad T, Aderdour L, Nouri H, Rochdi Y, et al. Retropharyngeal abscess in adults: five case reports and review of the literature. ScientificWorldJournal. 2011; 11:1623-9.

7 Sanz Sánchez CI, Morales Angulo C. Retropharyngeal abscess. clinical review of twentyfive years. Acta Otorrinolaringol Esp. 2021 Mar-Apr;72(2):71-79.

8 LeRiger MM, Miler V, Tobias JD, Raman VT, Elmaraghy CA, Jatana KR. Potential for severe airway obstruction from pediatric retropharyngeal abscess. Int Med Case Rep J. 2017; 10:381-4.

9 Al-Sabah B, Bin Salleen H, Hagr A, ChoiRosen J, Manoukian JJ, Tewfik TL. Retropharyngeal abscess in childrean: 10-year study. The J Otolaryngol. 2004 Nov;33:352-5.
10 Pontell J, Har-El G, Lucente FE. Retropharyngeal abscess: clinical review. Ear Nose Throat J. 1995;74(10):701-4.

11 Philpott CM, Selvadurai D, Banerjee AR. Paediatric retropharyngeal abscess. J Laryngol Otol. 2004;118(12):919-26.

12 Craig FW, Schunk JE. Retropharyngeal abscess in children: clinical presentation, utility of imaging, and current management. Pediatrics. 2003;111(6 Pt 1):1394-8.

13 Page NC, Bauer EM, Lieu JE. Clinical features and treatment of retropharyngeal abscess in children. Otolaryngol Head Neck Surg. 2008; 138(3):300-6.

14 Ali NE, Alyono JC, Koltai PJ. Neonatal retropharyngeal abscess with complications: apnea and cervical osteomyelitis. Int J Pediatr Otorhinolaryngol. 2019;126(109613):109613.

15 Dawes LC, Bova R, Carter P. Retropharyngeal abscess in children. ANZ J Surg. 2002;72(6): $417-20$.
16 Daniel R, Stokes P, Dhillon K, Walsh P. The accuracy of lateral X-ray and computed tomography in diagnosis of paediatric retropharyngeal abscess: a systematic review. Aust J Otolaryngol. 2020;3:12.

17 Page C, Biet A, Zaatar R, Strunski V. Parapharyngeal abscess: diagnosis and treatment. Eur Arch Otorhinolaryngol. 2008;265(6):681-6.

18 Sichel JY, Dano I, Hocwald E, Biron A, Eliashar R. Nonsurgical management of parapharyngeal space infections: a prospective study. Laryngoscope. 2002;112(5):906-10.

19 McClay JE, Murray AD, Booth T. Intravenous antibiotic therapy for deep neck abscesses defined by computed tomography. Arch Otolaryngol Head Neck Surg. 2003;129(11):120712.

20 Wilkie MD, De S, Krishnan M. Defining the role of surgical drainage in paediatric deep neck space infections. Clin Otolaryngol. 2019 May;44(3):366-71. 